\title{
“Cachaças” (Sugarcane Spirit) Aged Quantitation of Phenolic Compounds, Antibacterial and Antioxidant Activity
}

\author{
Leonardo Milani Avelar Rodrigues ${ }^{1}$, Maria das Graças Cardoso ${ }^{2}$, Luís Roberto Batista1, \\ Wilder Douglas Santiago², Juliana Maria Valério Resende', Juliana de Andrade Santiago², \\ Marcos de Souza Gomes², Milene Aparecida Andrade², Maria Luisa Teixeira², \\ Fabiana Reinis Franca Passamani1
}

${ }^{1}$ Department of Food Science, Federal University of Lavras, Lavras, Brazil

${ }^{2}$ Department of Chemistry, Federal University of Lavras, Lavras, Brazil

Email: ${ }^{*}$ mcardoso@dqi.ufla.br

Received 15 July 2014; revised 17 August 2014; accepted 29 August 2014

Copyright (C) 2014 by authors and Scientific Research Publishing Inc.

This work is licensed under the Creative Commons Attribution International License (CC BY).

http://creativecommons.org/licenses/by/4.0/

(c) (i) Open Access

\section{Abstract}

The "cachaça" is currently one of the fastest growing agro-industrial industries in the country as the drink considered as a symbol of Brazilian nationality. This study aimed to quantify the phenolic compounds, evaluate the antioxidant and antibacterial activity of different samples of aged "cachaça". The physic-chemical analysis was performed at the Brandy Quality Laboratory of the Federal University of Lavras, and the determination of phenolic compounds was performed by High Performance Liquid Chromatography (HPLC). The antimicrobial activity evaluation was held at the Food Mycology Laboratory through the cavity agar diffusion technique and by steam using the micro-organisms Escherichia coli, Staphylococcus aureus, Salmonella choleraesuis, Listeria monocytogenes and Pseudomonas aeruginosa. The antioxidant activity was evaluated using the DPPH radical sequestering method. The values obtained for the phenolic compounds ranged from 0.41 to $9.69 \mathrm{mg} / \mathrm{L}$, observing the predominance of syringaldehyde, gallic acid and vanillic acid. The phenolic extracts showed a satisfactory antibacterial activity for both Gram-negative and Grampositive but did not show inhibition against the bacteria Pseudomonas aeruginosa. The antioxidant activity was evidenced by the DPPH test for cachaças tested and the "cachaça" aged in oak barrel showed the highest activity, followed by "cachaça" aged in jequitibá, amburana and balm barrels.

\section{Keywords}

Syringaldehyde, Gallic Acid, Vanillic Acid, Bacteria, DPPH Test

\footnotetext{
${ }^{*}$ Corresponding author.

How to cite this paper: Rodrigues, L.M.A., Cardoso, M.G., Batista, L.R., Santiago, W.D., Resende, J.M.V., Santiago, J.A., Gomes, M.S., Andrade, M.A., Teixeira, M.L. and Passamani, F.R.F. (2014) “Cachaças" (Sugarcane Spirit) Aged Quantitation of Phenolic Compounds, Antibacterial and Antioxidant Activity. American Journal of Plant Sciences, 5, $2935-2942$. 


\section{Introduction}

The cane brandy is a distilled-yeast beverage originated at the slavery time. It is currently one of the fastest growing agro-industrial industries in the country, and is considered as a symbol of Brazilian nationality, being the most consumed distilled in the country, much appreciated for its characteristic taste and aroma. According to the Normative Instruction No. 13, June 30, 2005, the sugarcane brandy is the beverage with an alcohol content of $38 \%$ to $54 \%$ at $20^{\circ} \mathrm{C}$ obtained from a simple alcoholic distillate from sugar cane in which can be added sugars to $6 \mathrm{~g} \cdot \mathrm{L}^{-1}$; and the "cachaça” is defined as every brandy of sugarcane that has an alcohol content of $38 \%$ to $48 \%$ by volume [1].

This drink aging process does not depend solely on the wood species used to store the brandy, but other factors such as the residence time of it inside the barrels. In this process, various chemical reactions occur providing the extraction of phenolic compounds from the wood, as well as adding value to the product and improving the sensory characteristics [2].

The phenolic compounds are present in different plant tissues and may have some biological properties as antioxidants, anticarcinogenic, antiteratogenetic and antimicrobial depending upon the chemical structures. Several phenolic compounds have been applied in foods, as chemical preservatives, aiming microbial stability, in addition of presenting high nutritional value. Therefore, it is necessary to conduct more comprehensive studies related to the antimicrobial activity and its effects on various micro-organisms that are impacting health of these compounds.

Given the above, the purpose of this study is to characterize and quantify the phenolic compounds aged in "cachaça” in different wood types and evaluate the antioxidant and antibacterial activity.

\section{Material and Methods}

Four samples were collected from aged “cachaça”, directly from the producing units in the south of Minas Gerais from different wood barrels and with distinct capabilities. The wood used for drink storage was: oak (180 months), amburana (96 months), balm (36 months) and jequitiba (24 months). The physico-chemical and microbiological analysis were performed at the Brandy Quality Laboratory and Food Mycology Laboratory at the Federal University of Lavras.

\subsection{Quantification of Phenolic Compounds}

The methodology used for analysis of phenolic compounds in "cachaça” samples stored in different types of wooden barrels was described by Anjos et al. (2011). The standard stock solutions were prepared at a concentration of $1000 \mathrm{mg} / \mathrm{L}$ in $40 \%$ ethanol at the following concentrations: gallic acid $(6.80 \mathrm{mg} / \mathrm{L})$, catechin $(11.61$ mg/L), vanillic acid (6.73 mg/L), phenol (3.76 mg/L), syringic acid (7.93 mg/L), vanillic acid (6.08 mg/L), syringaldehyde $(7.29 \mathrm{mg} / \mathrm{L})$, p-coumaric acid $(6.56 \mathrm{mg} / \mathrm{L})$, sinapic acid $(8.97 \mathrm{mg} / \mathrm{L})$, coumarin $(5.85 \mathrm{mg} / \mathrm{L})$, 4-methylumbelliferone $(7.05 \mathrm{mg} / \mathrm{L})$ and o-coumaric acid $(6.56 \mathrm{mg} / \mathrm{L})$.

Methanol used for quantification was the external standardization. For the construction of analytical curves, intermediate dilutions were made containing a mixture of all standard, and this was achieved by diluting the stock solutions prepared in advance. The samples and standard were filtered on a polyethylene membrane of $0.45 \mu \mathrm{m}$ and directly injected into the chromatographic system.

The injections were performed in triplicate and the identity of analytes was confirmed by retention time and sample peaks compared to the standard ones. Elution solvents used were: $2 \%$ acetic acid solution in water (solvent A) and methanol:water:acetic acid (70:28:2\% v/v) (solvent B). The samples and standards were eluted under gradient from 0 to $25 \min (00 \%$ - 40\% B), 25 - 40 min (44\% - 55\% B), 40 - 50 min (55\% - $100 \%$ B), 50 - 60 $\min (100 \%-00 \%$ B). The wavelength used was $280 \mathrm{~nm}$, flow of $1.25 \mathrm{~mL} / \mathrm{min}$, injection volume $20 \mu \mathrm{L}$ and run time of $60 \mathrm{~min}$, held at a temperature of $40^{\circ} \mathrm{C}$.

\subsection{Antioxidant Activity}

The antioxidant activity was determined according to the methodology proposed by Lin et al. (2005) [3]. It was added $3.12 \mathrm{~mL}$ of DPPH solution (2,2-diphenyl-picryl-hidrazine) 0.004\% (0.004 g of DPPH for $100 \mathrm{~mL}$ in 95\% ethanol) with $0.3 \mathrm{~mL}$ sample. It was added $0.3 \mathrm{~mL}$ of $95 \%$ ethanol for control with no sample. It was incubated for $10 \mathrm{~min}$ in the dark at $30^{\circ} \mathrm{C}$ and absorbance was measured after 60 minutes at $515 \mathrm{~nm}$ (Shimadzu UV-160- 
1PC). All analysis was performed in triplicate. The $\%$ of inhibition was calculated as follows:

$$
\% \text { inhibition }=\frac{A_{\text {control }}-A_{\text {sample }}}{A_{\text {control }}} \times 100
$$

where: $A_{\text {control }}=$ control absorbance and $A_{\text {ample }}=$ sample absorbance.

\subsection{Obtaining the Phenolic Extracts of Aged "Cachaça"}

Aliquots of aged "cachaça” were placed in a water bath at a temperature of $60^{\circ} \mathrm{C}-70^{\circ} \mathrm{C}$ for an indefinite period in order to eliminate the total alcohol content obtaining the extract concentrated of non-volatile phenolic compounds [1].

\subsection{Biological Activity of Phenolic Extracts}

The evaluation of antibacterial activity of phenolic extracts was held at the Food Mycology Laboratory of Department of Food Science, of the Federal University of Lavras.

The bacteria used were Escherichia coli ATCC 11229, Staphylococcus aureus ATCC 13565, Salmonella choleraesuis ATCC 6539, Listeria monocytogenes ATCC 19117 and Pseudomonas aeruginosa ATCC 15442. During the experiment, the microorganisms were kept in eppendorfs containing freezing media under refrigeration $\left(4^{\circ} \mathrm{C}\right)$. For activation of cultures the strains were peaked in Brain Heart Infusion broth (BHI) and incubated at $37^{\circ} \mathrm{C}$ for 24 hours. After activation, platings were performed in specific media for each species (National Committee for Clinical Laboratory Standards) [4].

\subsection{Standardization of Inoculum}

Cultures of Escherichia coli ATCC 11229, Staphylococcus aureus ATCC 13565, Salmonella cholerasuis ATCC 6539, Listeria monocytogenes ATCC 19117 and Pseudomonas aeruginosa ATCC 15442 were standardized employing the McFarland $0.5 \mathrm{BaSO}_{4}$ scale. The active culture was peaked for brain broth infusion (BHI) and incubated at $37^{\circ} \mathrm{C}$ for 24 hours. Subsequently, an aliquot of $300 \mu \mathrm{L}$ was transferred to Triptic Soy Broth (TSB). This was again incubated under the same conditions being monitored every half hour according to the scale of 0.5 McFarland $\mathrm{BaSO}_{4}$ solution up to a concentration of $10^{8} \mathrm{UFC} \mathrm{mL}^{-1}$. This was diluted until they reached a concentration of $10^{6} \mathrm{UFC} \mathrm{mL}{ }^{-1}$. Later, it was held in agar plating (TSA Triptic Soy Agar) for the Listeria monocytogenes and Pseudomonas aeruginosa species, and for other species we used Mueller-Hinton agar, for inoculum concentration confirmation (National Committee for Clinical Laboratory Standards).

\subsection{Cavity Diffusion in Agar Test}

The inhibitory effect of phenolic extracts was determined using the methodologies of cavity diffusion in agar and diffusion per steam. In this analysis, the methodology used was the cavity diffusion in agar using the TSA agar (Triptic Soy Agar) for the Listeria monocytogenes and Pseudomonas aeruginosa species, and for other species, Müeller-Hinton agar [5].

A thin layer of agar was added to Petri plates (140 mm diameter). After solidification, sterile glass beads of 4 mm diameter were placed on solid media. Standardized aliquots of cultures of Escherichia coli ATCC 11229, Staphylococcus aureus ATCC 13565, Salmonella Cholerasuis ATCC 6539, Listeria monocytogenes ATCC 19117 and Pseudomonas aeruginosa ATCC 15442, were transferred to erlemeyers containing $200 \mathrm{~mL}$ of Mueller-Hinton agar or TSA yielding concentration of $10^{6} \mathrm{UFC} / \mathrm{mL}$. The media still liquid was poured over the previous layer. After solidification of agar, the glass beads were removed with sterile forceps and then taken to phenolic extracts deposition into the formed wells. The dilutions were carried out in a dimethylsulfoxide (DMSO) solution using the following proportions: pure extract, 1:1, 1:2, 1:4, 1:8, 1:16, yielding the respective concentrations of 1000 (pure extract) 500; 250; 125; 62.5; $31.25 \mu \mathrm{L} / \mathrm{mL}$. They were applied in wells of $10 \mu \mathrm{L}$ of diluted extract. For each extract used it was held a control solution consisting of $1 \%$ DMSO. The plates were incubated in a BOD $37^{\circ} \mathrm{C}$ for 24 hours and measured the diameters of inhibition halos formed. Three replicates were performed for each treatment on a control with the application of $10 \mu \mathrm{L}$ of DMSO; as a comparison standard, we used a solution of $100 \mu \mathrm{g} / \mathrm{mL}$ of chloramphenicol antibiotic (CL) [6]. 
Since the diameter formed by the action of phenolic extracts which showed a sensitivity of microorganism, it can be evaluated the bacteria sensitivity at different concentrations of extracts. The Minimum Inhibitory Concentration (MIC) was defined as the lowest concentration of extract with the presence of inhibition halo.

\section{Results and Discussion}

\subsection{Quantification of Phenolic Compounds}

The Figure 1 shows the chromatogram of phenolic compounds standard solution for spectrophotometric detection obtained after injections of $20 \mu \mathrm{L}$. According to the chromatogram we can observe the phenolic compounds separation in analysis. Table 1 describes the values of limit detection of analytical curves (b, $a$ and $\mathrm{R}^{2}$ ) and the values of detection limit (LOD) and quantification in $\mathrm{mg} / \mathrm{L}$. The analytical curves' equations were calculated by the method of minimum squares, measuring the detector's response (area) versus concentration after injection of solutions in triplicate containing all standards. Correlation coefficients were obtained ranging from 0.992 to 0.999 , demonstrating the strong linear correlation between the concentration of compound analyzed and the peak area as recommended in the literature [6].

In all analyzed wood you can observe the predominance of different phenolic compounds. Table 1 presents the phenolic compounds values of aged "cachaça". The differences can be explained due to factors such as type of wood used in the aging, barrel ability, storage time of the beverage, size and pre-treatment of barrel, environmental conditions as temperature and humidity of storage environment and alcohol content of the beverage. These related parameters influence the composition of phenolic compounds extracted from wood during the aging process of the beverage [7].

In "cachaça" aged in oak barrels, it has been observed the predominance of syringaldehyde $(9.69 \mathrm{mg} / \mathrm{L})$ and gallic acid $(6.32 \mathrm{mg} / \mathrm{L})$; in amburana, vanillic acid $(4.71 \mathrm{mg} / \mathrm{L})$ and coumarin $(4.08 \mathrm{mg} / \mathrm{L})$ in the vanillic acid balm $(8.74 \mathrm{mg} / \mathrm{L})$ and gallic acid $(7.48 \mathrm{mg} / \mathrm{L})$ in jequitibá syringaldehyde $(2.11 \mathrm{mg} / \mathrm{L})$ and gallic acid $(1.49$ $\mathrm{mg} / \mathrm{L}$ ). These results are in accordance with those obtained by Anjos et al. (2011) [8], and Santiago et al. (2012) [9] in which differences were found for the presence and concentration of phenolic compounds in "cachaça" aged in different wood species. According to Zacaroni et al. (2011) [8] the contents of compounds extracted

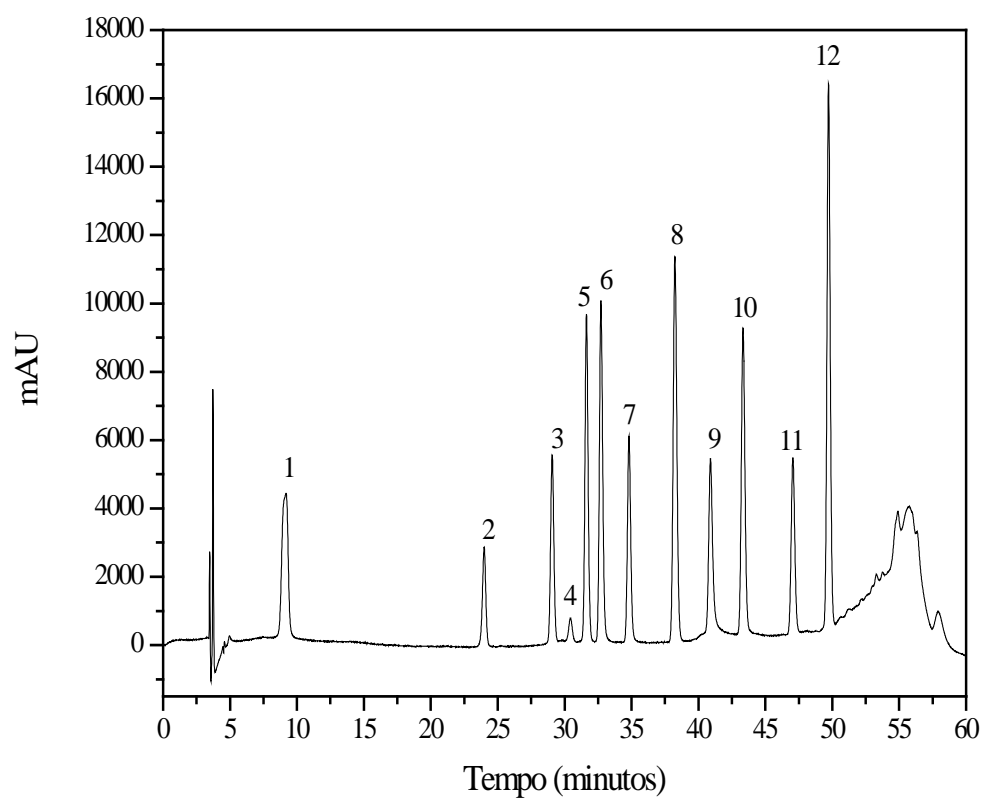

Figure 1. Chromatogram of a phenolic compound standard solution with spectrophotometric detection. Identification of peaks: 1) gallic acid, 2) catechin, 3) vanillic acid, 4) phenol, 5) syringic acid, 6) vanillin, 7) syringaldehyde, 8) p-coumaric acid, 9) sinapic acid, 10) coumarin, 11) 4-methylumbelliferone and 12) o-coumaric acid. The concentration of each standard was: $1161 \times$ $10^{-5} \mathrm{~mol} / \mathrm{L}$. 
Table 1. Phenolic composite analyzed by high performance liquid chromatography in aged "cachaça” in oak, amburana, balm and jequitibá barrel.

\begin{tabular}{|c|c|c|c|c|c|c|c|c|}
\hline $\begin{array}{l}\text { Phenolic } \\
\text { compound }\end{array}$ & $\begin{array}{c}\text { Oak } \\
\text { mg/mL }\end{array}$ & $\mathrm{SD}$ & $\begin{array}{c}\text { Amburana } \\
\text { mg/mL }\end{array}$ & $\mathrm{SD}$ & $\begin{array}{c}\text { Balm } \\
\mathrm{mg} / \mathrm{mL}\end{array}$ & SD & $\begin{array}{c}\text { Jequitiba } \\
\text { mg/mL }\end{array}$ & $\mathrm{SD}$ \\
\hline Gallic acid & 6.326 & \pm 0.032 & 1.366 & \pm 0.053 & 7.484 & \pm 0.053 & 1.492 & \pm 0.053 \\
\hline Catechin & 0.726 & \pm 0.012 & 3.287 & \pm 0.015 & 2.235 & \pm 0.001 & $<\mathrm{LQ}$ & \pm 0.001 \\
\hline Vanillic acid & 1.729 & \pm 0.086 & 4.717 & \pm 0.081 & 8.740 & \pm 0.008 & 0.974 & \pm 0.008 \\
\hline Phenol & 4.609 & \pm 0.027 & 0.312 & \pm 0.023 & 3.347 & \pm 0.023 & 0.954 & \pm 0.023 \\
\hline Syringic acid & 4.874 & \pm 0.043 & 2.301 & \pm 0.001 & 0.964 & \pm 0.000 & 1.067 & \pm 0.006 \\
\hline Vanillin & 1.671 & \pm 0.052 & 0.190 & \pm 0.050 & 1.329 & \pm 0.050 & 0.443 & \pm 0.050 \\
\hline Syringaldehyde & 9.691 & \pm 0.021 & 1.099 & \pm 0.022 & 0.872 & \pm 0.022 & 2.118 & \pm 0.022 \\
\hline P-coumaric acid & $<\mathrm{LQ}$ & \pm 0.039 & $<\mathrm{LQ}$ & \pm 0.003 & 1.498 & \pm 0.003 & 0.419 & \pm 0.003 \\
\hline Sinapic acid & 1.120 & \pm 0.014 & 3.210 & \pm 0.019 & 0.982 & \pm 0.019 & $<\mathrm{LQ}$ & \pm 0.019 \\
\hline Coumarin & 0.239 & \pm 0.023 & 4.089 & \pm 0.032 & 1.345 & \pm 0.032 & $<\mathrm{LQ}$ & \pm 0.032 \\
\hline 4-Methyl umbelliferone & $<\mathrm{LQ}$ & \pm 0.095 & 2.008 & \pm 0.008 & $<\mathrm{LQ}$ & \pm 0.008 & $<\mathrm{LQ}$ & \pm 0.008 \\
\hline O-coumaric acid & 0.055 & $\pm 0,042$ & $<\mathrm{LQ}$ & \pm 0.003 & $<\mathrm{LQ}$ & \pm 0.003 & $<\mathrm{LQ}$ & \pm 0.003 \\
\hline
\end{tabular}

Media \pm standard deviation; SD = Standard Deviation.

from wood increase with aging time and increase of contact surface between beverage/wood, which can be explained for the oak sample that has a higher aging time.

The main compounds found in the "cachaça" aged in oak were syringaldehyde and gallic acid which were probably incorporated into the beverage during the storage time. Anjos et al. (2011) [8], researched "cachaça" samples aged in oak barrels and showed that syringaldehyde and gallic acid were the compounds that showed higher concentration, results that corroborate with those found in this work.

Subsequently, Santiago et al. (2012) [9] analyzed two samples of "cachaça” aged in oak barrels observed that the major main compounds present in the samples were syringaldehyde and gallic acid, confirming the found results. The difference in the amount of these compounds may be directly related to the storage time. These results are in agreement with those found by Madrera et al. (2003) [10] who observed differences in the contents and in the presence of gallic acid and syringaldehyde during aging in addition to the presence of derivatives of cinnamic aldehyde present in the distillated beverage as brandy with different storage times.

One factor that affects the aging of "cachaça" is wood. This, as a material of complex structure formed by cell wall materials (cellulose, polyposis and lignin) and various different extractives (phenolic compounds, steroids, terpenes, etc.) shows a distribution of compounds in different ways depending on the age of the plant. Therefore, in addition to the factors mentioned above, the phenolic compounds presence in the beverage may be related to the wood position (near the shell, bone, top or bottom) used in the barrels production, as well as the tree age to obtain the wood. The species of wood can vary, as its morphology, fiber size, thickness of cell wall that may be obstructed preventing beverage penetration and that this contact with extractive substances and cell wall consequently reduces the compounds incorporation to the beverage [11].

\subsection{Antioxidant Activity of Aged Cachaças Extract}

The four types of wood exhibited a similar antioxidant activity behavior as time elapsed. Through the variance analysis, there was a significant difference $(p<0.05)$ between both types of wood as assessed times. The antioxidant activity increased with the analysis time, i.e., there was a dose-dependent effect related to the tested times (Figure 2). By contrast, when analyzing this activity among wood types in each time, the antioxidant activity varied significantly in accordance to the used time. The "cachaça" aged in balm barrel presented the highest value (66.750 \pm 0.31 ) of antioxidant activity at all times followed of woods, jequitibá (57.413 \pm 0.36 ), ork (51.308 \pm 0.18$)$, and amburana (49.621 \pm 0.82$)$.

\subsection{Inhibitory Effect of Phenolic Extracts of Microorganisms}

From the data of Table 2 it is observed that the minimum inhibitory concentration for the extract of oak, balm and amburana to the Staphylococcus aureus bacteria was $125 \mu \mathrm{g} / \mathrm{mL}$ not occurring inhibition for the Pseudo- 


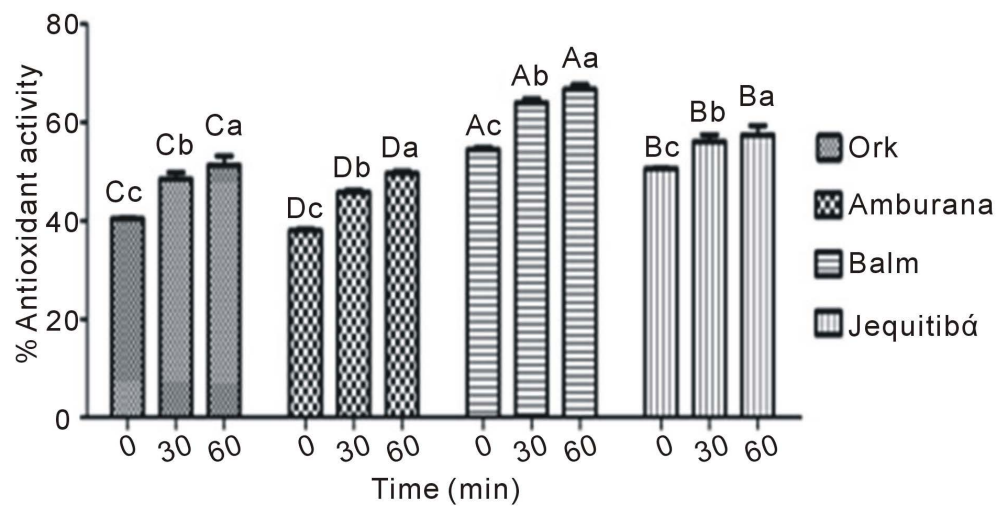

Figure 2. Antioxidant activity of "cachaças" aged in different types of wood and analyzed at different times media followed by the same letter, lowercase between times and uppercase between types of wood, did not differ significantly at $5 \%$ of probability by Scott-Knott test.

Table 2. Minimal inhibitory concentration of "cachaça” extract aged in barrels of oak, amburana, balm and jequitibá found for microorganisms Staphylococcus aureus, Listeria monocytogenes, Escherichia coli, Pseudomonas aeruginosa and Salmonella choleraesuis.

\begin{tabular}{|c|c|c|c|c|c|}
\hline \multicolumn{2}{|l|}{ Samples } & \multicolumn{4}{|c|}{ MIC ( $(\mu \mathrm{g} / \mathrm{mL})$} \\
\hline Bac & S. $a u$ & L. mon & E.co & S. cho & P. au \\
\hline Gram & + & + & - & - & - \\
\hline Oak & 125 & 500 & 1000 & 1000 & NI \\
\hline Amb & 125 & 500 & 500 & 500 & NI \\
\hline Balm & 125 & 500 & 500 & 500 & NI \\
\hline Jeq & NI & NI & NI & NI & NI \\
\hline CL & I & I & I & I & I \\
\hline DMSO & NI & NI & NI & NI & NI \\
\hline
\end{tabular}

NI: no inhibition occurred; I: inhibited; CL: chloramphenicol; DMSO: dimethylsulfoxide.

monas aeruginosa bacteria.

According to the results, it was observed a significant inhibition of extract of oak, balm and amburana on the Staphylococcus aureus, Listeria monocytogenes, Escherichia coli and Salmonella choleraesuis bacteria. Probably this inhibition occurred by the presence of phenolic compounds, gallic acid, syringaldehyde, syringic acid and phenol present in the extracts. These data corroborate those found by Vaquero et al. (2007) [12] who studied the inhibition of microorganisms by coumaric acid and p-coumaric acid, gallic acid and syringaldehyde extracted from plants. It was observed a small activity of these compounds facing pathogenic bacteria such as Salmonella choleraesius, Escherichia coli, Staphylococcus aureus, and Bacilus cereus.

Subsequent works of Barbosa (2010) [13] showed that the gallic acid component of the secondary metabolism of plants presented antioxidant property and some antimicrobial and parasitic activities. In the research, the author concluded that gallic acid is able to inhibit the respiratory chain of the Trypanossoma cruzi parasite also having antimicrobial activity against Escherichia coli.

Pelczar et al. (1997) [14] searching the antimicrobial activity of phenol and its derivatives showed that these compounds have the ability to damage the microbial cells resulting in an alteration of selective permeability of cytoplasmic membrane causing a loss of vital intracellular substances. Sroka and Cisowski (2003) [15] discuss that the effectiveness of phenolic compounds depends on the structural properties such as the position of hydroxyl group on the aromatic ring. These authors believe that the higher the hydroxylation of phenols degree the greater toxicity for microorganism.

According to Holley and Patel (2005) [16], the antibacterial activity of phenolic compounds and its action mechanism is not completely understood, it can be considered that the action mode of antimicrobial agents is established considering one of three following parameters as: compound reaction with the cell membrane caus- 
ing an increase of permeability and loss of constituent cell, inactivation of enzyme systems or essential enzymes including those involved in the energy production and synthesis of structural compounds or inactivation/destruction functional of genetic material. For Burt (2004) [17], there is consensus that aromatic and phenolic compounds act on cytoplasmic membranes changing the structure and function in active transport and coagulate the cell content. This author reports that Gram-positive bacteria are more susceptible to the activity of phenolic extracts than Gram-negative bacteria.

Gram-negative bacteria have an outer membrane, which causes a hydrophilic surface due to the presence of lipopolysaccharide molecules. However, small hydrophilic solutes are able to pass through this outer membrane through hydrophilic pores formed by membrane protein channels. Thus, it is considered that the outer membrane serves as a penetration of macromolecules barrier and hydrophobic compounds, and it is for this reason that Gram-negative bacteria are relatively resistant to antibiotics and other hydrophobic drugs, as well as phenolic compounds [18].

\section{Conclusions}

The main compounds found in aged "cachaça” were syringaldehyde (9.69 mg/L oak), vanillic acid (4.71 mg/L amburana), vanillic acid ( $8.74 \mathrm{mg} / \mathrm{L}$ balm) and syringaldehyde (2.11 mg/L jequitibá).

The antioxidant activity was evidenced by the DPPH test for cachaças tested and the "cachaça" aged in oak barrel showed the highest activity, followed by "cachaça” aged in jequitibá, amburana and balm barrels.

The phenolic extracts showed considerable biological activity on the Staphylococcus aureus, Listeria monocytogenes, Escherichia coli, and Salmonella choleraesuis bacteria, but were not effective against Pseudomonas aeruginosa.

\section{Acknowledgements}

To the Research Support Foundation of the State of Minas Gerais (FAPEMIG), to the National Council for Scientific and Technological Development (CNPq) and the Coordination of Higher Education Personnel Improvement (CAPES) for the financial support and scholarship granted. "Cachaça” Artesanal João Mendes for the availability of "cachaça" samples.

\section{References}

[1] Brasil Ministério da Agricultura, Pecuária e Abastecimento (2005) Instrução Normativa No. 13.

[2] Parazzi, C., et al. (2008) Avaliação e caracterização dos principais compostos químicos da aguardente de cana-deaçúcar envelhecida em tonéis de carvalho (Quercus sp.). Ciencia e Tecnologia de Alimentos, 28, 193-199. http://dx.doi.org/10.1590/S0101-20612008000100028

[3] Lin, Y.T., Vantten, D., Labbe, R.G. and Shetty, K. (2005) Enhancement of Antioxidant Activity and Inhibition of Helicobacte Pylori by Phenolic Phytochemical-Enriched Alcoholic Beverages. Process Biochemistry, 40, 2059-2065. http://dx.doi.org/10.1016/j.procbio.2004.07.019

[4] National Committee for Clinical Laboratory Standards (2003) Methods for Dilution Antimicrobial Susceptibility Tests for Bacteria That Grow Aerobically: Approved Standard. 6th Edition, Clinical and Laboratory Standards Institute, 2738.

[5] Pereira, A.A., et al. (2008) Caracterização química e efeito inibitório de óleos essenciais sobre o crescimento de Staphylococcus aureus e Escherichia coli. Ciência e Agrotecnologia, 32, 887-893. http://dx.doi.org/10.1590/S1413-70542008000300028

[6] Sndyder, L.R., Kirkland, J.J. and Glajch, J.L. (1997) Practical, HPLC Method Development. Wiley, New York. http://dx.doi.org/10.1002/9781118592014

[7] Miranda, M.B., Horii, J. and Alcarde, A.R. (2006) Estudo do efeito da irradiação gamma ( ${ }^{60}$ Co) na qualidade da “cachaça” e no tonel de envelhecimento. Ciencia e Tecnologia de Alimentos, 26, 772-778. http://dx.doi.org/10.1590/S0101-20612006000400010

[8] Anjos, J.P., et al. (2011) Evolution of the Concentration of Phenolic Compounds in "Cachaça” during Aging in an Oak (Quercus sp.) Barrel. Journal of the Brazilian Chemical Society, 22, 1307-1314. http://dx.doi.org/10.1590/S0103-50532011000700016

[9] Santiago, W.D., et al. (2012) Perfil físico-químico e quantificação de compostos fenólicos e acroleína em aguardentes de cana-de-açucar armazenadas em tonéis de diferentes madeiras. Cient, 40, 189-197. 
[10] Zacaroni, L.M., et al. (2011) Caracterização e quantificação de contaminantes em aguardentes de cana. Química Nova, 34, 320-324. http://dx.doi.org/10.1590/S0100-40422011000200026

[11] Madrera, R.R., Gomis, D.B. and Alonso, J.J.M. (2003) Characterization of Cider Brandy on the Basis of Aging Time. Journal of Food Science, 68, 1958-1961.

[12] Vaquero, M.J.R., Alberto, M.R. and Manca de Nadra, M.C. (2008) Antibacterial Effect of Phenolic Compounds from Different Wines. Food Control, 18, 93-101. http://dx.doi.org/10.1016/j.foodcont.2005.08.010

[13] Barbosa, V.F., et al. (2010) Caracterização do perfil da ação do ácido gálico e seus derivados sobre processos oxidativos in vitro e ex vivo. M.Sc. Dissertation, Faculdade de Ciências Farmacêuticas, UNESP, Araraquara, São Paulo.

[14] Pelczar, M.J., Chan, E.C.S. and Krieg, N.R. (1997) Microbiologia. Conceitos e aplicações. Editora Pearson, São Paulo.

[15] Sroka, C. and Cisowski, W. (2003) Hydrogen Peroxide Scavenging, Antioxidant and Anti-Radical Activity of Some Phenolic Acids. Food and Chemical Toxicology, 41, 753-758. http://dx.doi.org/10.1016/S0278-6915(02)00329-0

[16] Holley, A. and Patel, D. (2005) Improvement in Shelf-Life and Safety of Perishable Foods by Plant Essential Oils and Smoke Antimicrobial. Food Microbiology, 22, 273-292.

[17] Burt, S. (2004) Essential Oils: Their Antibacterial Properties and Potential Applications in Foods-A Review. International Journal of Food Microbiology, 94, 223-253.

[18] Mann, C.M., Cox, S.D. and Markham, J.L. (2000) The Outer Membrane of Pseudomonas aeruginosa NCTC 6749 Contributes to Its Tolerance to the Essential Oil Melaleuca alternifolia (Tea Tree Oil). Letters in Applied Microbiology, 30, 294-297. 
Scientific Research Publishing (SCIRP) is one of the largest Open Access journal publishers. It is currently publishing more than 200 open access, online, peer-reviewed journals covering a wide range of academic disciplines. SCIRP serves the worldwide academic communities and contributes to the progress and application of science with its publication.

Other selected journals from SCIRP are listed as below. Submit your manuscript to us via either submit@scirp.org or Online Submission Portal.
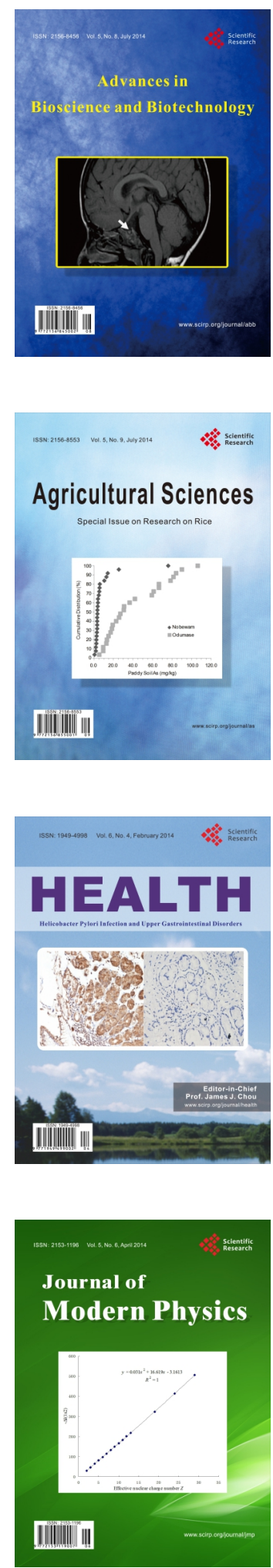
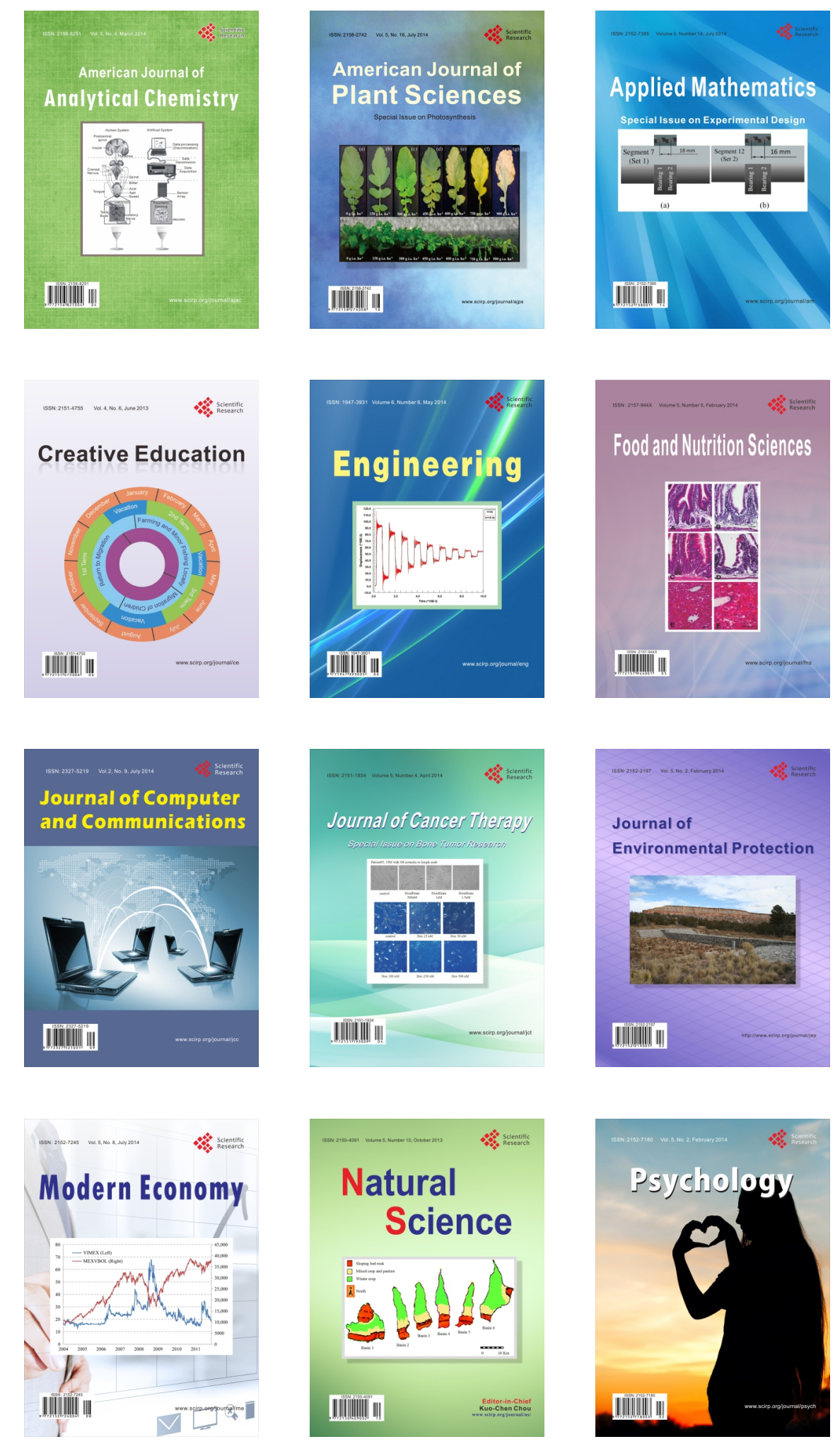